\title{
REABSORCIÓN RADICULAR INTERNA: REPORTE DE CASO
}

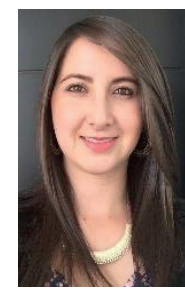

ODONT. KAROL CARRILLO RENGIFO POSGRADO EN ENDODONCIA UNIVERSIDAD CENTRAL DEL ECUADOF

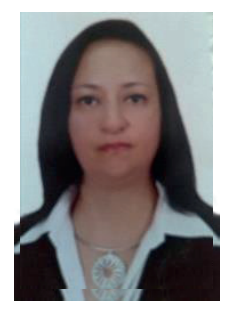

DRA. MARÍA VERÓNICA HERRERA DOCENTE DE POSGRADO UNIVERSIDAD CENTRAL DEL ECUADOR

\section{Resumen}

Introducción: La reabsorción radicular interna es una rara condición patológica de los dientes permanentes, causada por la actividad clástica de las células presentes en la pulpa $(1,2,3,4,5)$. Su etiología y patogénesis todavía no se ha dilucidado(1). El tejido pulpar en el sitio de la reabsorción se encuentra vital. El diagnóstico de la enfermedad se basa principalmente en el examen radiográfico. Este reporte de caso describe el tratamiento de un incisivo central superior con reabsorción radicular interna no perforante. Materiales y métodos: Primera cita se realiza un desbridamiento quimio-mecánico del conducto radicular, irrigación con $\mathrm{NaOCl} 5,25 \%$ y activación de la solución con ultrasonido. Se realiza una obturación con la técnica de onda continua de gutapercha termoplastificada. Resultados: Se elimina todo el tejido pulpar instrumentando conformando el conducto hasta una lima tipo $\mathrm{K} \# 50$, activando la solución irrigadora con ultrasonido y se realiza una obturación con gutapercha termoplastificada 


\section{Introducción}

La reabsorción radicular interna, es una rara condición patológica de los dientes permanentes causada por la actividad clástica de las células presentes en la pulpa, que promueve una desmineralización de tejido duro; debido a una inflamación pulpar $(1,2,3,4,5)$. Su etiología y patogénesis todavía no se ha dilucidado, se han propuesto diversos factores etiológicos, incluyendo traumatismos, caries e infecciones periodontales, resecciones radiculares vitales, anacoresis, tratamiento ortodóncico(1).

El estímulo para que ésta se produzca es la inflamación de la pulpa. Se ha dividido en Reabsorción inflamatoria interna, que radiográficamente se la observa como una ampliación oval, y Reabsorción interna de reemplazo en la que se observa el contorno del conducto distorsionado de apariencia difusa, con aposición de un tejido duro metaplásico semejante a hueso o cemento(6,7).

Los osteoclastos son los responsables de la reabsorción ósea, son reclutados en el sitio de lesión por la liberación de muchas citoquinas pro inflamatorias y se unen a la superficie del hueso mediante un citoesqueleto de actina $(9,10)$.

El tejido pulpar en el sitio de la reabsorción se encuentra vital, de esta manera la lesión progresa debido al rico suministro sanguíneo y célu- las sanguíneas que posee el tejido pulpar. Si no se trata la reabsorción interna puede continuar, hasta que el tejido conectivo inflamado degenere, haciendo avanzar la lesión perforando el conducto radicular (10).

El diagnóstico de la enfermedad se basa principalmente en el examen radiográfico, con información complementaria obtenida de la historia y los hallazgos clínicos. Se puede establecer un diagnóstico diferencial radiográficamente ya que la mayor diferencia radica en los bordes de la lesión. En la reabsorción radicular interna los bordes son bien definidos y la lesión se observa circunscrita, a diferencia de la reabsorción radicular externa en la se observan bordes irregulares y asimétricos (10).

Cuando el estímulo para que se produzca la reabsorción es retirado, sumado a una correcta preparación quimio-mecánica, una irrigación con $\mathrm{Na} . \mathrm{OCl}$ activando la solución con ultrasonido $(8,10)$; más la colocación de medicación intraconducto (9) y por último una obturación tridimensional sellando herméticamente el sistema de conductos, el pronóstico a largo plazo es favorable $(9,10)$. Este reporte de caso describe el tratamiento de un incisivo central superior con reabsorción radicular interna no perforante. La tomografía de haz cónico (Cone Beam) se usa para mejorar el diagnóstico radiográfico.

\section{Reporte del caso}

Paciente de 54 años de género masculino acude a la Clínica de Posgrado de Endodoncia de la Facultad de Odontología de la Universidad Central del Ecuador para el tratamiento del diente \# 11.

En su historia de la enfermedad refiere haber sufrido un trauma en el sector anterior en su niñez; con ausencia de sintomatología posterior, presenta una prótesis provisional fija y refiere que hace un año y medio presentó un tracto fistuloso, acudió a un subcentro de salud donde le remiten a la Facultad de Odontología de la Universidad Central del Ecuador, en pregrado le retiran la prótesis y diagnostican que debe reali- zarse una endodoncia en un diente pilar y como hallazgo radiográfico encuentran una reabsorción radicular interna razón por la cual remiten al posgrado de Endodoncia.

Al examen clínico el diente numero 1.1 es asintomático a la percusión, y masticación, la profundidad del sondaje se encuentra dentro de los límites normales al igual que los tejidos circundantes, con ausencia de patologías o alteraciones, no presenta movilidad. Pruebas de sensibilidad (calor y frío) negativas.

El examen radiográfico no muestra presencia de sombras radiolúcidas en apical, pero se observa 
una sombra radio lúcida en la mitad del conducto radicular que es comparable con una reabsorción radicular interna (Figura $1 \mathrm{~A}$ ).

Se realiza un examen $A B$ radiográfico de tomografía Cone Beam donde se constata la presencia de una reabsorción radicular interna, que no comunicaba con el periodonto, es decir no perforante (Figura $1 \mathrm{~B}$ ).

\section{Primera cita}

Previa anestesia infiltrativa submucosa maxilar, se realiza el aislamiento absoluto del campo operatorio (Figura $2 \mathrm{~A}$ ). Se retira la restauración provisional y se corrige el acceso. Irrigación con $\mathrm{NaOCl}$ al $5,25 \%$ y se procede a permeabilizar el conducto con una lima tipo K número 10 (Dentsply Maillefer), y se toma la longitud de trabajo electrónicamente con el localizador Root ZX ( $\mathrm{J}$ Morita, Irvine, CA) (Figura 2 B). La longitud se establece a $17,5 \mathrm{~mm}$ con referencia del borde incisal.

\section{Segunda cita}

Después de 8 días, previa anestesia infiltrativa submucosa maxilar y aislamiento absoluto del campo operatorio se retira la restauración provisional, se accede al conducto y se retira la medicación intraconducto irrigando con $\mathrm{NaOCl}$ al $5,25 \%$, activando la solución con ultrasonido, y se adapta el cono maestro (figura 4 A y B). Posterior a esto se realiza la irrigación con EDTA $17 \%$ por 5 minutos y luego irrigación con $\mathrm{NaOCl}$ al $5,25 \%$ por tres minutos y se activa la solución irrigadora; se seca el conducto con puntas capillary (Ultradent) y se procede a obturar con técnica termoplastificada.

Se realiza la obturación con onda continua de calor y como cemento sellador se utiliza AdSeal (MetaBiomed). Se introduce el cono maestro junto con el cemento en el conducto y se procede a cortar los $4 \mathrm{~mm}$ en apical con el sistema de obturación Kansmile (Down Pack), se hace una radiografía de control (Figura $4 \mathrm{C}$ ) y posterior a esto se procede a inyectar gutapercha termo-
Se le informa el plan de tratamiento al paciente el mismo que, consta de la realización de la endodoncia y obturación con gutapercha termo plastificada; siendo el mismo aceptado por el paciente.

Se realiza la instrumentación del conducto con limas tipo K hasta la lima \# 50 en apical y con una lima Protaper SX se instrumenta la zona cervical del conducto proporcionando conicidad al mismo. Entre cada lima se irrigó profusamente con $\mathrm{NaOCl}$ y se activa la solución con Ultrasonido (DTE D5) (Figura 3 A), se seca el conducto y se coloca hidróxido de calcio (Ultracal) (Figura 3 B) y una restauración con cemento provisional Obtura.

plastificada en el conducto (Back Fill), cada tres milímetros se toma una radiografía de control (Figura 4 D) hasta que el conducto queda lleno totalmente y se hace una radiografía final (Figura 4 E). Se coloca como restauración cemento provisional Obtura y se remite a pregrado para la rehabilitación correspondiente.

A

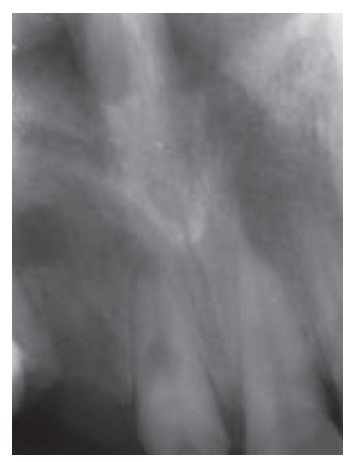

B

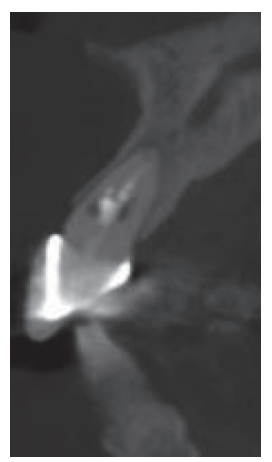

FIG 1:

(A) Radiografía periapical inicial

(B) Imágen tomográfica inicial Cone Bean del diente a nivel del incisivo superior muestra la presencia de una reabsorción radicular interna 
A

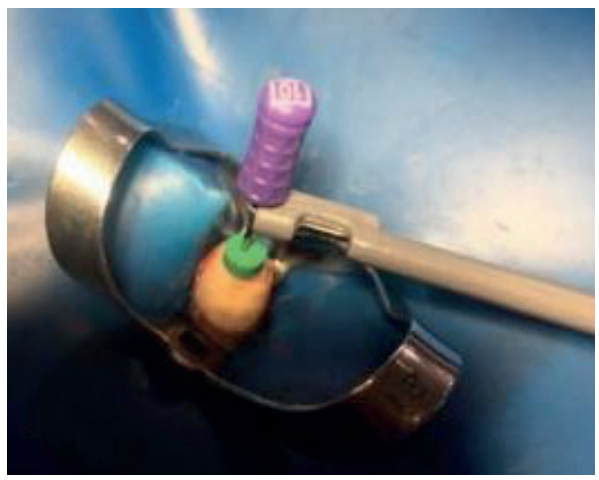

A

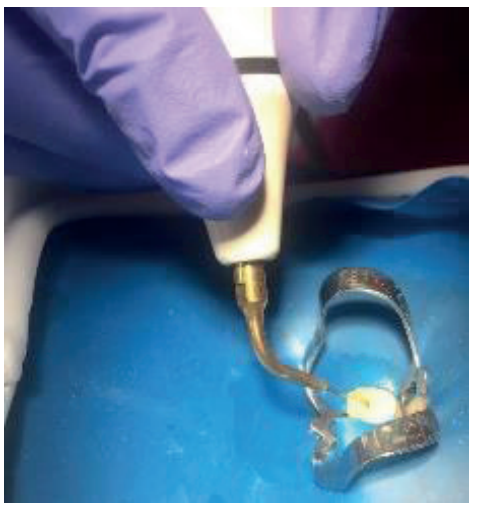

B

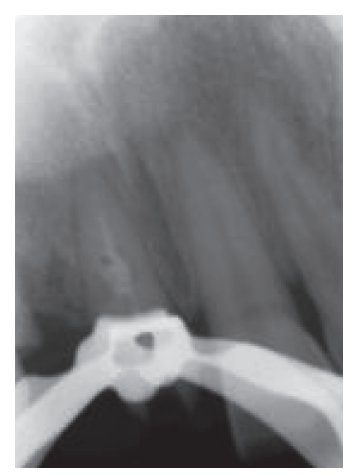

A

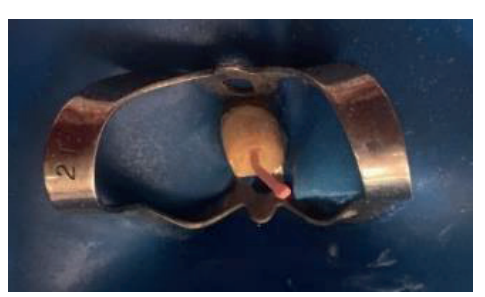

B

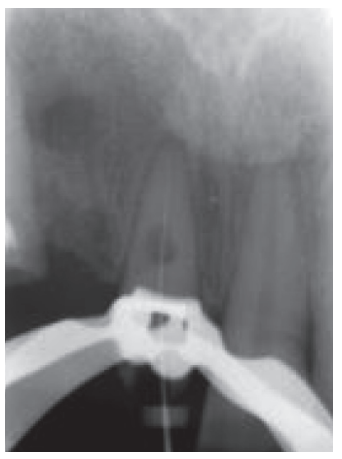

Figura 2:

(A) Aislamiento Absoluto y toma de Longitud de trabajo con localizador Root ZX Morita . (C) Radiografía periapical comprobando longitud de trabajo
FIG 3.:

(A) Activación de la solución irrigadora con ultrasonido (DTE D5). (B) Radiografía periapical de la colocación de Hidróxido de Calcio en el conducto radicular
C

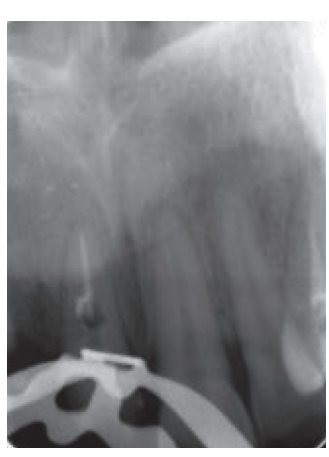

B

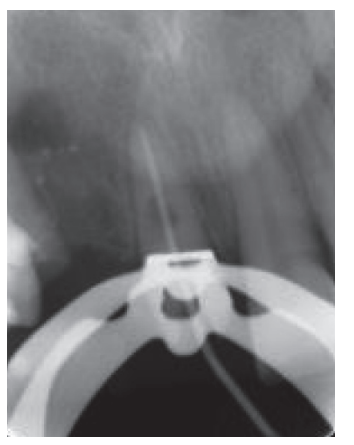

D

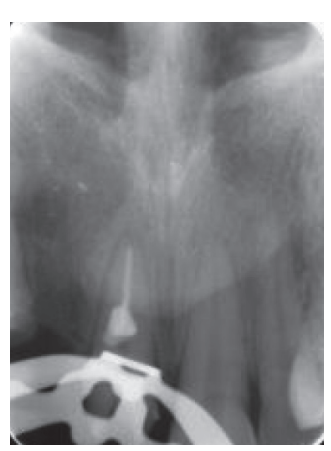

E

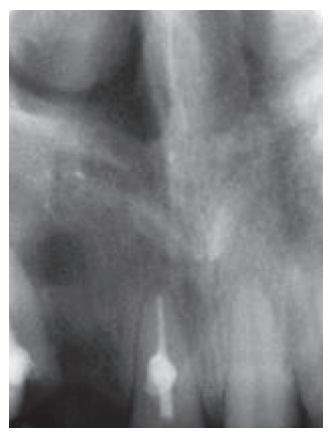

FIG 4:

(A-B) Conometría. (C) Radiografía periapical de obturación termoplastificada Down Pack 4mm del conducto radicular. (D) Inyección de gutapercha termoplastificada Back Fill cada $3 \mathrm{~mm}$. (E) Radiografía periapical final. 


\section{Discusión}

Se han propuesto distintas hipótesis acerca del origen de la reabsorción radicular interna, pero todavía no se ha encontrado en concreto su etiología, diversas investigaciones la asocian a una lesión traumática. (3).

En este caso la lesión de reabsorción radicular interna también se la puede asociar a un trauma sufrido por el paciente en su niñez. En la actualidad el uso de la tomografía de haz cónico (10) ayuda a un diagnóstico preciso y adecuado de las patologías dentales existentes, ya que gracias a este examen radiográfico podemos observar en tres dimensiones; lo que facilita el diagnóstico y tratamiento a tiempo de esta patología $(7,8)$.

Para que la reabsorción radicular interna se detenga, es importante retirar el estímulo que induce a la destrucción de tejido. Esto se logra con el tratamiento del conducto radicular; eliminando cualquier resto de tejido pulpar vital que pueda estar presente; uno de los pasos muy importantes dentro del tratamiento es la irrigación con hipoclorito de sodio al 5,25\% para eliminar los restos de tejido presente, barrillo dentinario y bacterias que alberga el conducto (5). Por esta razón la activación ultrasónica del irrigante es un paso esencial en la desinfección del conducto. (9)

Sin embargo con la activación ultrasónica las bacterias y restos de tejido pueden todavía permanecer dentro del conducto, de igual manera la reabsorción radicular interna se da por la activación de células clásticas que van a destruir el tejido mineralizado; por lo tanto un medicamento intracanal debe ser utilizado para una desinfección adecuada del conducto radicular y una inactivación de las células clásticas.
El hidróxido de calcio es un medicamento intracanal que ha demostrado un poder antibacteriano eficaz además inhibe la actividad de células clásticas gracias a su alcalinidad.

El objetivo de la obturación del sistema de conductos radiculares es un sellado hermético tridimensional, evitando así la reinfección; pero los conductos que presentan este tipo de patologías representan un desafío para el clínico al tratar de conseguir una obturación y un sellado tridimensional. Gencoglu (2008) encontró que la gutapercha termo plastificada fue el sistema de obturación más adecuado para sellar herméticamente este defecto $(1,5,4)$.

Se debe considerar una preparación mecánica conservadora del conducto, para mantener tejido dentinario que da soporte al diente.

El periodonto soporta solo diez grados centígrados más de la temperatura corporal normal antes de necrosarse, por lo tanto evitar esto realizando una preparación conservadora es imperativo, protegiendo así al ligamento periodontal cuando se realiza la obturación con gutapercha termo plastificada $(8,9,10)$

Se puede concluir que en el presente caso se eliminó el tejido pulpar inflamado, que es el estímulo que produce la reabsorción radicular interna, una irrigación y activación de la solución irrigadora es eficaz para una desinfección adecuada y la obturación con gutapercha termo plastificada es el método de obturación ideal para realizar un sellado tridimensional y hermético del conducto radicular. 


\section{BIBLIOGRAFÍA}

1. Patel S, Ricucci D, Durak C, Tay F. Internal Root Resorption: A Review. Journal of Endodontics 2010 6:1107- 1121

2. Da Silveira P, Boessio M, Montagner F, Dias da Silveira L, Dias da Silveira H. Development of a New In Vitro Methodology to Simulate Internal Root Resorption Journal of Endodics 2014;40:211-216

3. Sari S, Sönmez D. Internal Resorption Treated with Mineral Trioxide Aggregate in a Primary Molar Tooth: 18-Month Follow-Up. Journal of Endodontics 2006: 32:69 - 71

4. Meire M, De Moor R. Mi- neral Trioxide Aggregate Repair of a Perforating Internal Resorption in a Mandibular Molar. Journal of Endodontics 2008;34:220 -223

5. Gabor C, Tam E, Shen Y, Haapasalo M. Prevalence of Internal Inflammatory Root Resorption. Journal of Endodontics 2012;38:24- 27 6. Ne R, Witherspoon D, Gutman J. Tooth Resorption. Journal Quintessence International 1999; 30:9-25

7. Heithersay S. Management of tooth resorption. Australian Dental Journal Suppl ement 2007;52

8.

Caliskan MK, Turkun M.
Prognosis of permanent teeth with internal resorption: a clinical review. Endod Dent Traumatol 1997; 13: 75-81.

9. Boyce B, Xing L. Functions of RANKL/RANK JOPG in bone modeling and remodeling. Journal Archives of Biochemistry and Biophysics 2008; 473: 139-146

10. Tyrovola J, Spyropoulos M, Makou M, Perrea D. Root Resorption and the OPG

RANKL/RANK system: A mini review. Journal of Oral Science 2008; 50:4 367-376

* Responsabilidad de Autor 